\title{
Remote sensing-based studies coupled with field data reveal urgent solutions to avert the risk of flash floods in the Wadi Qus (east of Jeddah) Kingdom of Saudi Arabia
}

\begin{abstract}
On November 25, 2009, heavy amount of rainfall precipitated in the city of Jeddah that led to floods causing unexpected loss of life (113 person died), and damaged public and private properties (10,000 cars were damaged/destroyed, and many houses, roads, highways, and industrial properties were also affected). The city of Jeddah is located within an independent mega drainage basin with a surface area of $1,760 \mathrm{~km} 2$. This mega basin is divided into three major sub-basins (northern, middle, and southern). Wadi Qus is located in the southern subbasin with an area of $\sim 63 \mathrm{~km} 2$. It passes through many of the neighborhoods such as AlHarazat, Al-Sawaid, Queza, Al-Mesaid, Al-Haramin Highway, and the King Abdel Aziz University. These areas were severely damaged during the flash flood event in 2009. The current study deals with the determination of the best sites for the construction of flood control dams, followed by a number of detailed studies to ensure that these selected sites are appropriate. Geological, geotechnical, geophysical, and hydrological investigations were conducted to identify the types of rocks, the subsurface conditions, and the geotechnical properties of abutment and subsurface of soil and rock in the dam sites. The study found that there are three locations that can be appropriate for the construction of the flood control dams at Wadi Qus. Hydrological studies indicated that the runoff volumes for sub-basins B1, B2, and $\mathrm{B} 3$ are 2,102,709,1,023,156, and 4,868,304 m3, respectively, for 500-year return period and 2,356,081, 1,149,687, and 5,451,123 m3, respectively, for 1,000-year return period. Comparing these values with the reservoir volumes calculated from the detailed ground survey with different dam's height, it was found that dam's heights of $15.5,11.5$, and $13.5 \mathrm{~m}$ for dams Q01, Q02, and Q03, respectively, are adequate for different basin volumes for 1,000-year return periods. Finally, the conceptual designs have been prepared and recommended for these dams.
\end{abstract}

Keyword: Flash floods; Jeddah; Dams; Remote sensing; Hydrological study; GIS 